\title{
UN CONTEXTO FUNERARIO DEL HORIZONTE MEDIO PROCEDENTE DE CERRO COLORADO, HUACHO
}

\author{
Pieter D. VAN Dalen Luna \\ UnIVERSIDAD NACIONAL MAYOR DE SAN MARCOS \\ pvandalen2@hotmail.com \\ Roberto C. TELLo CuAdros \\ UNIVERSIDAD NACIONAL SAN CRISTÓBAL DE HUAMANGA \\ kalony22@hotmail.com \\ HANS G. GRADOS RODRÍGUEZ \\ UniVERSIDAD NACIONAL MAYOR DE SAN MARCoS \\ hans_231@hotmail.com
}

\section{RESUMEN}

Se presenta las características de un contexto funerario del Horizonte Medio recuperado del complejo funerario de Cerro Colorado, en el extremo meridional del valle de Huaura. Entre los años 2014 y 2015 el proyecto de Investigación Arqueológica Chancay-Huaral-Atavillos, logró excavar más de 2000 contextos funerarios de este extenso complejo funerario, el más grande de toda la costa central peruana.

Palabras claves: arqueología, valle de Huaura, contextos funerarios, Horizonte Medio, cultura Huaura.

\section{ABSTRACT}

The characteristics of a funerary context of the Middle Horizon recovered from the funerary complex of Cerro Colorado, at the southern end of the valley of Huaura is presented. Between 2014 and 2015 the Archaeological Research Project Chancay-Huaral-Atavillos, managed to dig more than 2,000 funerary contexts of this vast funerary complex, the largest in Peru's central coast.

KeYwords: archeology, Huaura Valley, funerary contexts, Middle Horizon, Huaura culture. 


\section{INTRODUCCIÓN}

Entre 2014 y 2015, durante el marco del Proyecto de Rescate Arqueológico denominado "Proyecto Arqueológico Complementario en la Asociación de Vivienda Los Pinos, Parcela 2 sitio arqueológico Cerro Colorado, distrito de Santa María", se llevaron a cabo excavaciones sistemáticas en diferentes calles y pasajes de cuatro asociaciones de vivienda; esto, con la finalidad de que esta población asentada allí, tras recuperar el 100\% de materiales culturales pueda obtener servicios básicos.

No obstante esto, la particularidad del espacio trabajado, destaca porque en realidad corresponde a un inmenso cementerio prehispánico con mayor preponderancia de la época Chancay, la misma que se ubica en las inmediaciones del sitio arqueológico de Cerro Colorado. En este sentido, las diversas unidades fueron abiertas en diferentes lugares correspondiente a las cuatro asociaciones de vivienda. En esta oportunidad, se dan a conocer los resultados del Contexto Funerario 12 correspondiente a la Unidad 13, la nos da nuevas luces para comprender las características del Horizonte Medio en el valle de Huaura. Con este artículo se pretende poner en conocimiento al público en general, sobre un aspecto importante de la cultura Huaura como es su patrón funerario.

\section{El complejo de Cerro Colorado: antecedentes de estudio}

El complejo arqueológico de Cerro Colorado se encuentra ubicado en el extremo sur del valle de Huaura, justo en el límite entre el valle mismo y las estribaciones andinas conocidas como Cerro Colorado por su tonalidad rojiza, producto de la gran cantidad de componentes férricos en proceso de oxidación al entrar en contacto con la garúa estacional y los vientos. Estos cerros son pequeñas elevaciones que llegan a alcanzar los 100 metros sobre el nivel del mar. Cerro Colorado es un extenso complejo arqueológico con extensas áreas funerarias, de almacenamiento y doméstico.

Por sus dimensiones y características podemos afirmar de Cerro Colorado que se constituye en el área funeraria más extensa de toda la costa central peruana, pues se extiende desde la quebrada de Pampa de Animas en el lado oriental hasta la misma línea de playa, abarcando todas las estribaciones conocidas como Cerro Colorado Grande, Cerro Colorado Chico, Las Antenas, San José de Manzanares y el área de la ciudad universitaria de la Universidad Nacional José Faustino Sánchez Carrión. Así pues, esta era el área de enterramiento de los antiguos pobladores del valle de Huaura, pues mientras los grandes centros políticos administrativos y residenciales se localizaban en medio del valle, como el complejo arqueológico Walmay, su población era enterrada en esta gran área funeraria en medio de grandes rituales.

A pesar que casi no hay arqueólogo que no haya escuchado hablar o haya visitado este complejo de Cerro Colorado, nadie ha realizado investigación arqueológica alguna, pues solo se conocen sus materiales a partir de proyectos de evaluación y rescates arqueológicos (Tosso 1997, Rodríguez 2007, Gonzales 2009, Morales 2009) o por la acción del huaqueo.

El área más importante se encuentra ubicado hacia el lado este de la carretera Panamericana, inmediatamente al ingresar a la ciudad de Huacho, terreno que hoy se encuentra ocupado por numerosos asentamientos humanos como es el caso de Alberto Fujimori Fujimori, Los Pinos, San Antonio, Las Palmeras Unidas y Cerro Colorado, los cuales cada año van avanzando y ocupando parte del cementerio huaqueado.

Esta área está conformada por numerosos contextos funerarios disturbados, observándose en superficie abundante material cerámico del estilo Chancay en sus tipos Negro sobre Blanco, Tricolor y Pasta Roja. Se aprecian además abundantes retazos de textiles que conformaban los fardos, de naturaleza llana o listados en color marrón sobre fondo crema, muy similar a la decoración de la cerámica. 
Esta área presenta también una edificación ortogonal de planta cuadrangular que corresponde a un tambo del periodo Tawantinsuyu. Cabe señalar que en la parte superior hay un conjunto de edificaciones en adobitos correspondientes al periodo Lima del Intermedio Temprano.

El año 2000 el arqueólogo Water Tosso Morales realizó el "Proyecto de Estudio de Evaluación Arqueológica en la modalidad de evaluación, Prospección y Reconocimiento sistemático con excavaciones en el Asentamiento Humano Alberto Fujimori“ (Tosso 2000), en el cual realiza la delimitación (sustentado con pozos de cateo) del área de complejo arqueológico ocupado por el Asentamiento Humano Alberto Fujimori Fujimori y áreas adyacentes. Asi mismo realiza una división del área por parcelas, en la cual La Parcela 1, corresponde al sitio arqueológico de Cerro Colorado, conformado por el tambo y el área funeraria adyacente, no ocupado por el asentamiento humano; la Parcela 2 conformada por el sector del área funeraria ocupada por el asentamiento humano Alberto Fujimori Fujimori, localizado en las áreas cercanas a la Carretera Panamericana Norte y terrenos agrícolas por donde hoy pasa la nueva Panamericana construida por Nor vial. Esta parcela 2 ha sido parcialmente rescatada por Rocío Gonzales (Gonzales 2007, Vallejo 2010) y Lucía Balbuena (Balbuena 2007) para la empresa Nor Vial, rescate que ha sido culminado por nosotros y del cual procede el contexto que describimos líneas abajo. La Parcela 3 está conformada por un área en forma de "L" localizado entre las Asociaciones de Vivienda Cerro Colorado y Las Palmeras Unidas, conformada por algunas construcciones y áreas funerarias aisladas, rescatada por Luis Rodríguez (Rodríguez 2007) y por Héctor Morales (Morales 2009). La Parcela 4 corresponde a una pequeña área aislada ubicada en los terrenos de la Asociación de Vivienda San Antonio, donde Tosso identificó un muro de tapiales. Por su parte la Parcela 5 corresponde al área sin evidencias arqueológicas, hacia el norte del terreno en mención, en parte de los terrenos de las asociaciones de Vivienda Las Palmeras Unidas, San Antonio y Alberto Fujimori Fujimori, el cual sin embargo presenta un remanente que ha sido rescatado hace tres años (van Dalen, Grados, Tello, Vivanco, Flores y Marcelo 2014). En un anterior trabajo (van Dalen y Carbonel 2015) hemos presentado los análisis de un individuo que murió de cáncer, recuperado cerca del contexto funerario que presentamos en el presente trabajo.

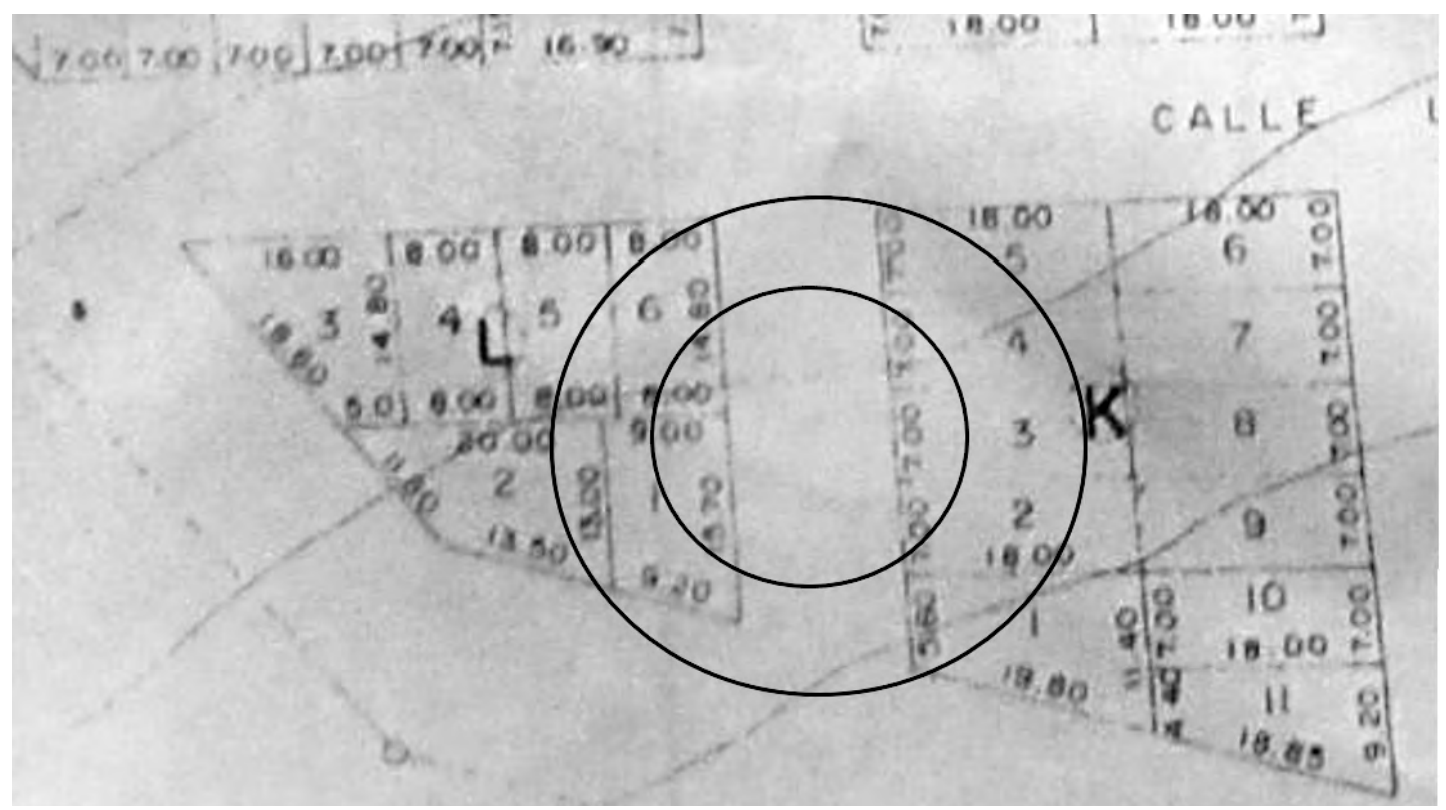

Figura 1. Ubicación de la unidad de excavación 13. 
Sobre los trabajos realizados en el marco del "Proyecto de Rescate Arqueológico Los Pinos" existen pocas referencias, pues a pesar de la gran cantidad de contextos funerarios hallados, Vallejo reporta más de 400 (Vallejo 2010: 238), los resultados no han sido publicados por completo. Francisco Vallejo (2010: 229-248) señala que estos contextos funerarios se hallaron asociados a una gran cantidad de materiales, principalmente vasijas, y colocados en el interior de estructuras funerarias simples, principalmente de planta circular $u$ ovalada. Los individuos se orientan por lo general hacia el este con ligera inclinación al norte, aunque hay algunos orientados al este, dispuestos en posición flexionada en variadas formas (Ibid: 238). Un aspecto de gran importancia es la definición de parte de Vallejo de un nuevo estilo local, denominado como "Estilo Huacho", correspondiente al Intermedio Tardío (del cual hablaremos más ampliamente en el capítulo VI).

Asimismo, en el área ocupada por el asentamiento Humano San José de Manzanares, al sur de la ciudad de Huacho, Martín Córdova (Córdova 2003) dirigió, primero el proyecto de evaluación arqueológica el año 2002, y luego el proyecto de Rescate Arqueológico el año 2003, en el área de la Plaza de Armas, en una unidad de 738.76 metros cuadrados. Córdova reportó el hallazgo de contextos funerarios, la mayor parte disturbados por las áreas de vivienda contemporáneas y por el huaqueo. Los seis contextos funerarios recuperados en contexto (Córdova; 2003: 2), consisten de entierros múltiples conformados por tres o más individuos ubicados a un metro de profundidad, correspondiente a clase social baja por no presentar materiales asociados. Se identificó tres capas (Ibid: 4), de las cuales las dos superiores (A y B) han sido disturbadas y la C corresponde a un uso como área funeraria durante el desarrollo de la cultura Chancay. En el pozo 10 de la evaluación arqueológica reportó el hallazgo de un entierro múltiple de cuatro individuos enfardelados, colocados en posición de cúbito dorsal, en fila y orientados hacia el este. Estos fardos son descritos de la siguiente manera (Ibid: 8):

"Fardo 01: Fardo de $1.67 \mathrm{~m}$ de largo, envuelto en telas llanas de color blanco. Presenta relleno de motas de algodón.

Fardo 02: Fardo de $1.60 \mathrm{~m}$ de largo, envuelto en telas llanas, de colores blanco, crema y marrón, con diseños de líneas paralelas horizontales. Sobre este individuo se hallaba colocado un paquete mortuorio enfardelado, de $1.05 \mathrm{~m}$ de largo que contendría los restos de un individuo infante.

Fardo 03: Fardo de 1.65 m de largo, envuelto en telas llanas de colores crema y marrón; con diseños de líneas horizontales paralelas.

Fardo 04. Fardo de $1.70 \mathrm{~m}$ de largo, corresponde al individuo de mayor tamaño. Se halla envuelto en telas llanas de colores blanco, crema y marrón, con diseños de líneas paralelas horizontales. Sobre este individuo se halló una estera de fibra vegetal enrollada y atada con una soguilla del mismo material"

Córdova (Ibid: 7) describe el hallazgo de numerosos adobes que habrían conformado los materiales constructivos de las estructuras funerarias, pero disturbadas por el huaqueo; aunque encontró también algunos muros de adobes en pie pero deteriorados por forados de huaqueo.

El Dr. Arturo Ruiz Estrada reportó desde inicios de la década del 80 (Ruiz 1981, 1990, 1991, 1998a, 1998b, 1999, 2007) el hallazgo de contextos funerarios en las inmediaciones del campus universitario de la Universidad Nacional José Faustino Sánchez Carrión de la ciudad de Huacho (denominado por el autor como cementerio número uno), algunos de estos con características muy peculiares. Uno de estos fue la recuperación del contexto funerario de un músico (Ruiz 1991: 133-153), el cual presentaba una estructura funeraria (T-76) a modo de fosa cilíndrica de 0.72 metros de alto y una boca de entre 0.74 y 0.84 metros de diámetro, mientras su fondo tenía entre 0.63 y 0.69 metros de diámetro. En su 
interior Ruiz halló dos fardos, el primero conteniendo en su interior a un individuo sentado y orientado al oeste, con la espalda apoyada en la pared sur, cabeza inclinada hacia abajo, extremidades superiores flexionadas al tronco y presionando dos zampoñas, las extremidades inferiores flexionadas entre sí, el cráneo presenta ligera deformación por aplastamiento del occipital. El fardo dos, presenta en su interior a otro individuo a espaldas del anterior y apoyado sobre sus rodillas (del primero), brazos flexionados al tronco y manos al mentón, piernas replegadas al vientre, cráneo deformado por aplanamiento del occipital, pero en general en mal estado de conservación. Los fardos se hallaban rellenados con totora y telas de algodón. En el medio de la estructura se halló cuatro vasijas asociadas tapadas con cuencos de base anular.

Sin embargo, ya en un informe anterior (Ruiz 1981: 1-14) reportó el hallazgo en este cementerio de 63 contextos funerarios con 69 fardos, ubicados en el interior de estructuras funerarias tipo pozo con piso simple y pozo de dos niveles, de formas variadas (elíptica, circular, rectangular y cuadrangular). Los fardos estaban conformados por varias capas de telas, las cuales envolvían a individuos con las extremidades flexionadas al cuerpo, caracterizadas por presentar cráneos con deformación y algunos con trepanación suprainiana, dientes con caries y paradenciopatía en el maxilar y mandíbula; así como huesos supernumerarios en la sutura lambdoidea. Algunos individuos presentaban tatuajes. Asociados a los fardos encontró en general 288 vasijas de naturaleza simple y con decoración negro sobre blanco (estilo Chancay), así como restos de alimentos (maíz, frijol, cucurbitácea, camote, yuca, maní, pescado y mariscos); instrumentos de madera para actividades agrícolas y textil (lisos, callhuas o espadas de tejedor, agujas, entre otros), láminas de metal, entre otros. Los textiles están elaborados en fibra de algodón principalmente y en técnicas reps, gasa, tapiz, doble tela, brocado, entre otros; decorados con motivos de aves y felinos estilizados, en motivos geométricos.

\section{LA UNIDAD DE EXCAVACIÓN 13}

La Unidad 13, se ubica en la Asociación de Vivienda Los Pinos IV Etapa, en la parcela 2 del complejo arqueológico de Cerro Colorado, entre las calles Los Héroes y Libertad. Comprende tres Sub Unidades: I, II y III. La Sub Unidad I, se ubica de este a oeste, en la calle Los Héroes; la Sub Unidad II, se ubica hacia el lado norte de la Sub Unidad I, en la calle Libertad; y la Sub Unidad III, se ubica hacia el lado sur de la Sub Unidad I, en la calle Libertad.

\section{Sub Unidad I}

La sub-unidad I de la unidad 13, se encuentra ubicada en la calle Los Héroes. En esta Sub Unidad se han registrado un total de 16 Contextos Funerarios, 1 hallazgo y 4 entierros, de los cuales en el presente artículo se da a conocer solo el contexto funerario 12. La secuencia estratigráfica identificada en la excavación es la siguiente:

Capa Superficial: Capa conformada por un estrato de origen antrópico (moderno), usada para el tránsito de la población y de los vehículos. Presenta como componentes naturales: arena fina, gravilla y basura moderna (papeles, plástico, latas, etc). Presenta una granulometría fina, de textura irregular y consistencia suelta. Hacia el lado norte de dicha Sub Unidad, se ubican tres postes de energía eléctrica y un silo; de igual forma, hacia el lado sur, se ubica un poste de energía eléctrica y un silo.

Capa: A: Se trata de una capa cultural (relleno cultural), con algunas evidencias de material moderno, conformado por componentes naturales como arena suelta en mayor cantidad, piedras pequeñas, raíces, material cultural prehispánico, en gran porcentaje fragmentos de cerámica (bordes, bases, asas, fragmentos del cuerpo), material textil, botánico, malacológico y restos de carbón. 


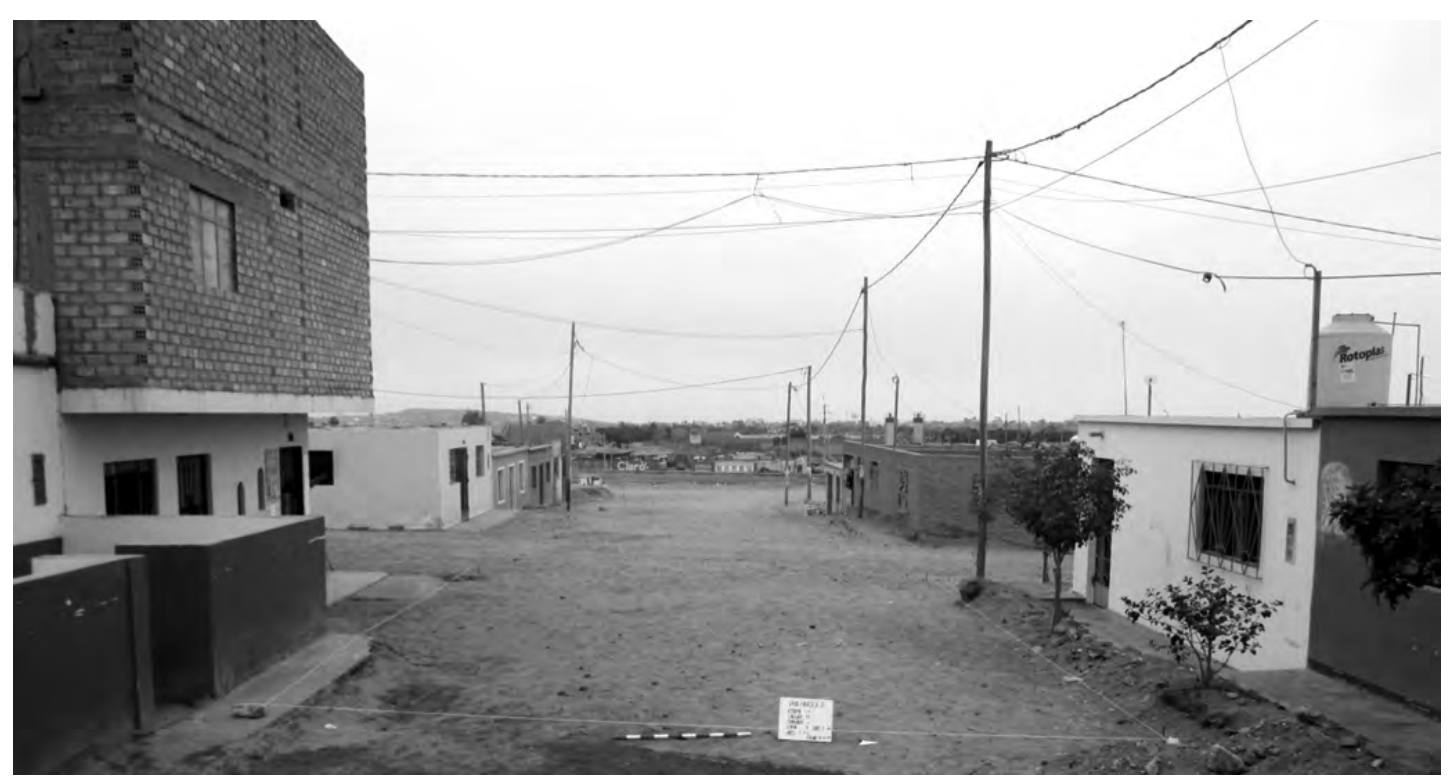

Figura 2: Vista panorámica de la capa S de la Sub Unidad I, unidad 13 (vista de este a oeste).

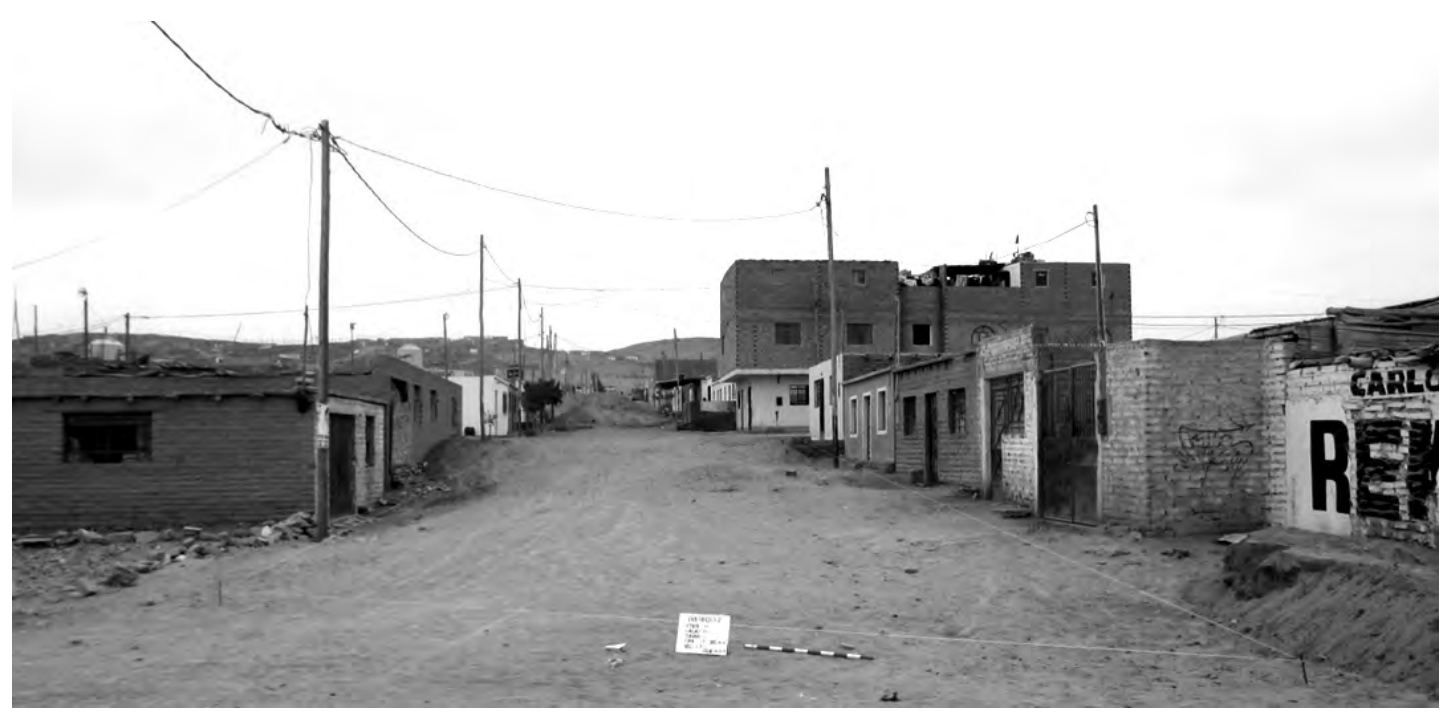

Figura 3: Vista panorámica de la capa S de la Sub Unidad I, unidad 13 (vista de oeste a este).

La presencia de material cultural se presenta en mayor proporción hacia el lado noroeste de dicha Sub Unidad, donde existe una mayor concentración de contextos funerarios encontrados, así como relleno de material botánico. El grosor de la capa es de 1.10 metros en promedio. Esta capa contiene los siguientes Contextos Funerarios: CF 01, CF 03, CF 04, CF 05, CF 06, CF 07, CF 08, CF 09, CF 10, CF 11, CF 12, CF 13, CF 14, CF 15 y CF 16. Los Hallazgos están denominados como: HAZ 2. Por su parte, los entierros están denominados como: ENT 01, ENT 02, ENT 03 y ENT 04. 


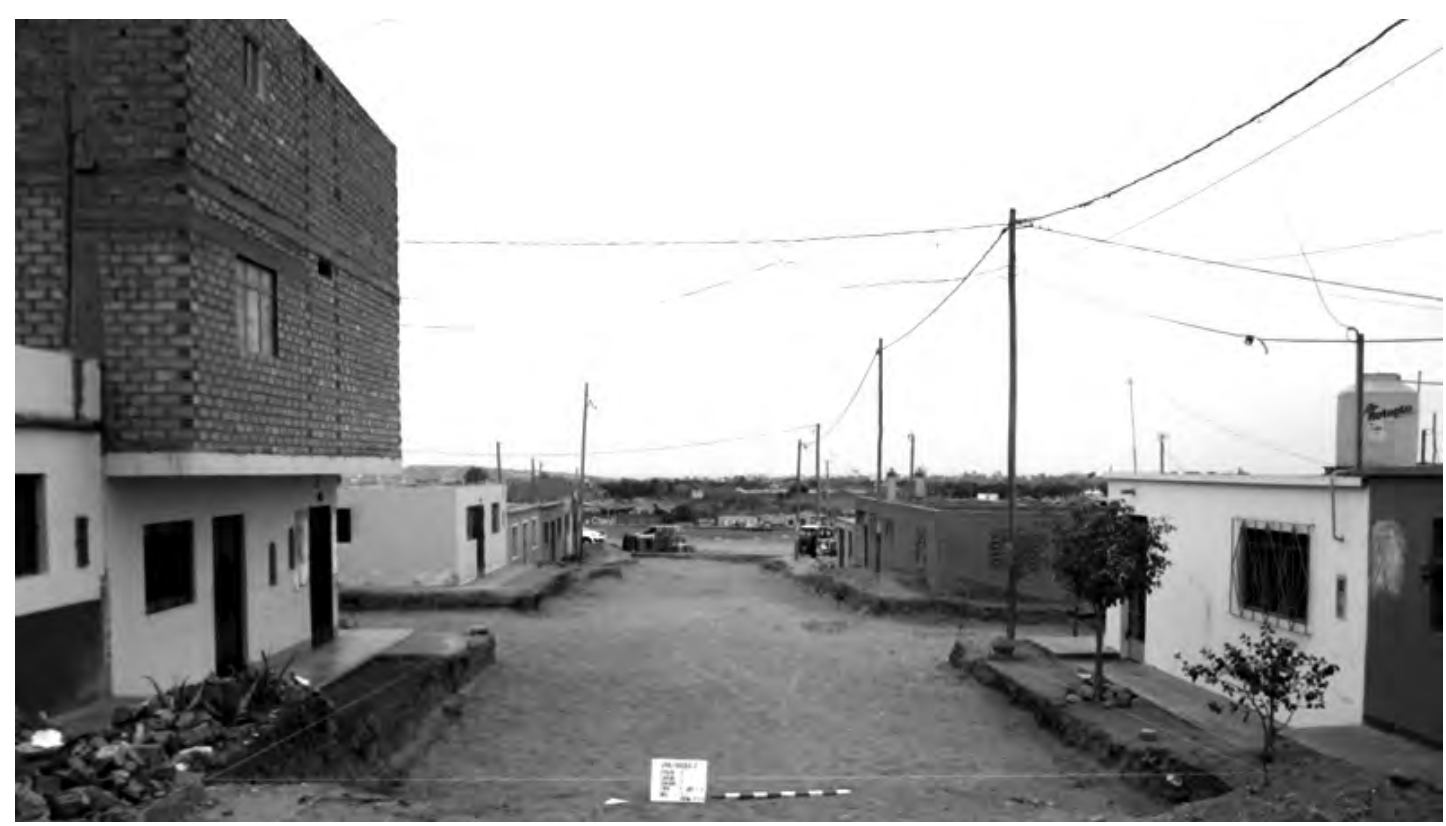

Figura 4: Vista panorámica de la capa A de la Sub Unidad I, unidad 13 (vista de este a oeste).

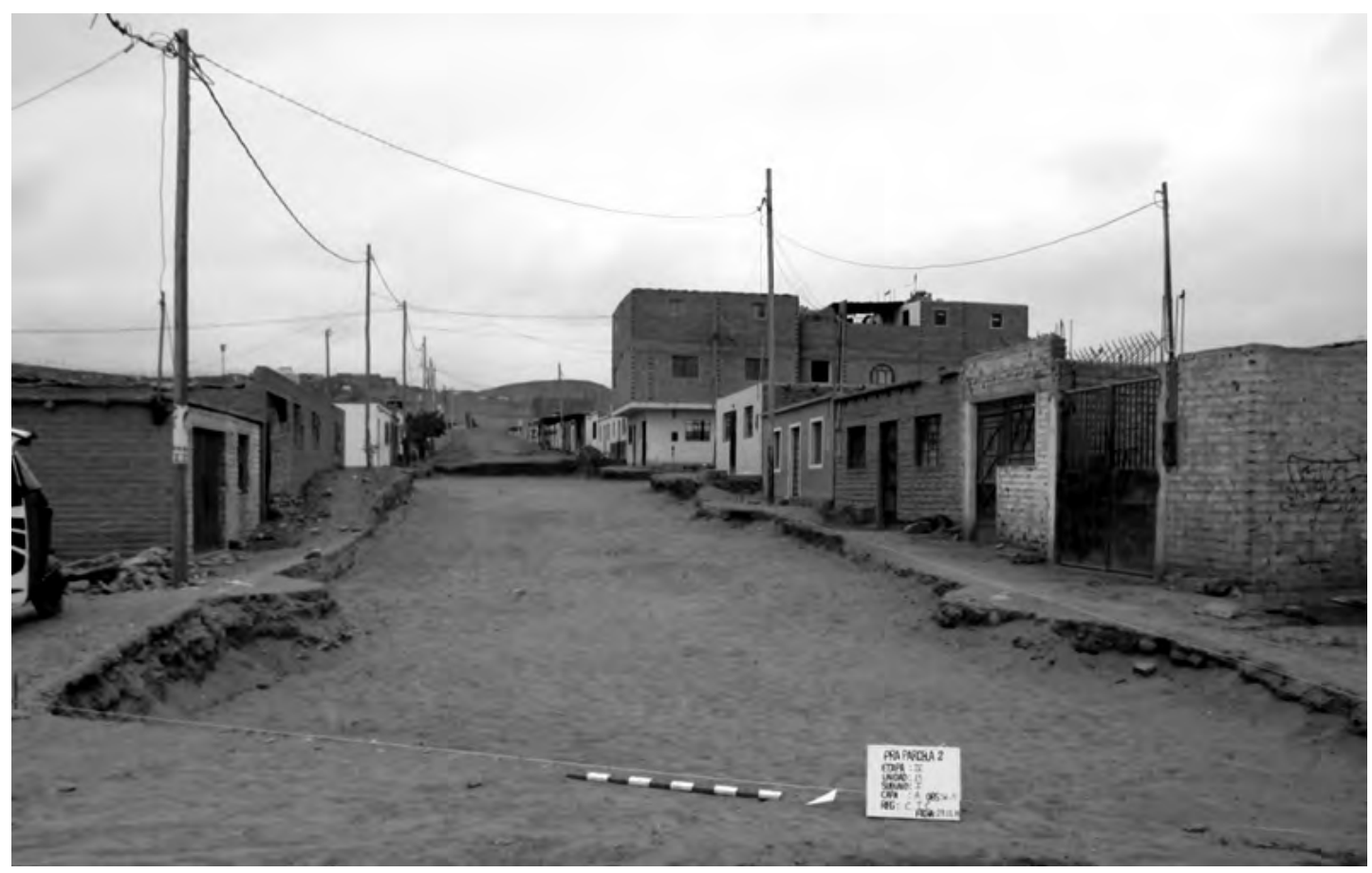

Figura 5: Vista panorámica de la capa S de la Sub Unidad I, unidad 13 (vista de oeste a este). 


\section{UN CONTEXTO FUNERARIO DEL HORIZONTE MEDIO}

El Contexto funerario 12 hallado en la Sub Unidad I de la Unidad de excavación 13 se localiza a 1.72 metros al oeste del límite de la Sub Unidad excavada y a 6.14 metros al sur del límite del mismo. La superficie de este contexto funerario se ubica a una profundidad de 3.06 metros con respecto a la cota de la unidad. Los componentes del contexto funerario son los siguientes:

Estructura Funeraria: Este contexto funerario no presenta una estructura funeraria definida, teniendo una matriz simple, la cual no intruye a otra capa geológica ya que se encuentra sobre la misma composición de la arena. Sin embargo, por la impronta dejada por la excavación, se nota que hubo un cuidado en la elaboración de dicha concavidad para depositar tanto al individuo como a los elementos respectivos. Es de planta circular, cuyo diámetro de norte a sur es de 0.80 metros, con una profundidad de 1.20 metros.

Para efectos de la excavación, está unidad fue dividida en tres niveles, tomando en cuenta la disposición de los materiales asociados (tres niveles de ofrendas).

Nivel I: Los componentes de este nivel son:

Individuo: En este nivel no se registró ningún individuo.

Asociaciones: Este nivel se identificó entre las asociaciones vasijas cerámicas (elementos) y troncos de madera dispuestos en posición vertical. Los troncos son de diversos tamaños y formas y se van profundizando hacia otros niveles inferiores a medida que se avanza con el proceso de excavación.

Elementos 1: Vasija de forma cerrada y acampanada invertida, hallada fragmentada. Presenta decoración externa variada con dos personajes antropomorfos. Los colores que presenta son el rojo, negro y crema. Esta vasija de estilo Huaura se dispone como tapa del elemento 2.

Elemento 2: Jarra de forma ovoide y estilo Huaura, presenta un asa cintada entre el cuello y la parte superior del cuerpo. Además, presenta signos de decoración en la parte externa. Junto con el elemento 1 , se encuentra hacia el lado sur de la estructura, junto con los troncos.

Elemento 3: Tazón de forma recto divergente y de boca ancha, es de color crema y se encuentra fragmentada. Se encuentra hacia el lado norte de la estructura, junto a los troncos y los anteriores elementos.

Nivel II: Los componentes de este nivel son:

Individuo: En este nivel no se registró ningún individuo.

Asociaciones: Este nivel se identificó entre las asociaciones vasijas cerámicas (elementos), metales (cobre) y los troncos de madera (extensión del nivel I) de diversos tamaños y formas.

Elemento 4: Vasija abierta en forma de escudilla de base cónica, se encuentra a manera de tapa del elemento 5 .

Elemento 5: Cántaro pequeño de cuerpo globular achatado, de cuello recto divergente. Presenta decoración variada en la parte exterior de su estructura.

Elemento 6: Olla pequeña de forma globular achatada, de cuello corto en forma acampanada, con dos asas cintadas laterales de forma vertical, presenta restos de quema en su estructura.

Elemento 7: Olla pequeña de forma globular achatada, de cuello corto en forma acampanada. 


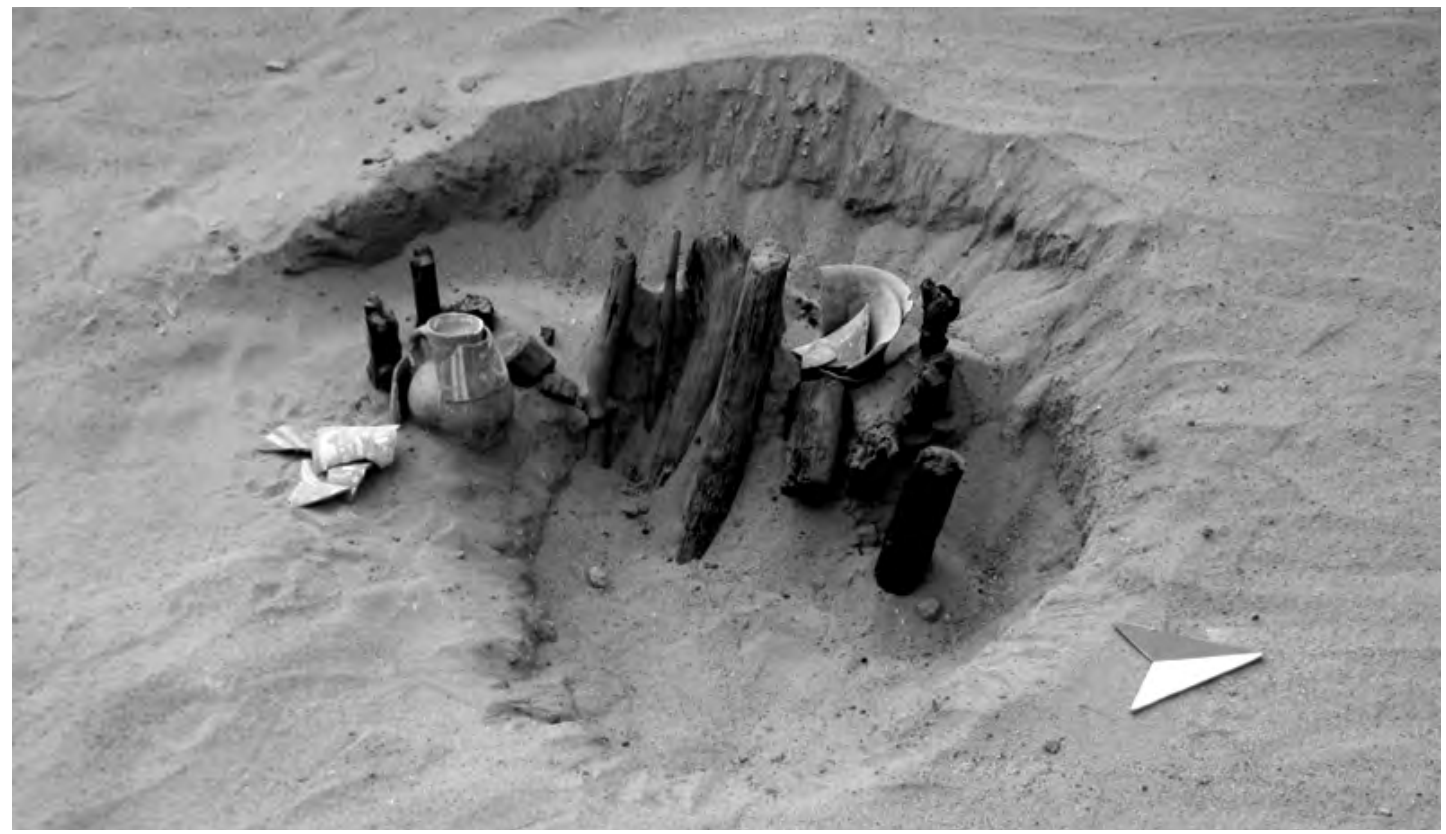

Figura 6: Vista en detalle del Nivel I, Contexto Funerario 12, Unidad 13, Cerro Colorado. Nótese la matriz funeraria.

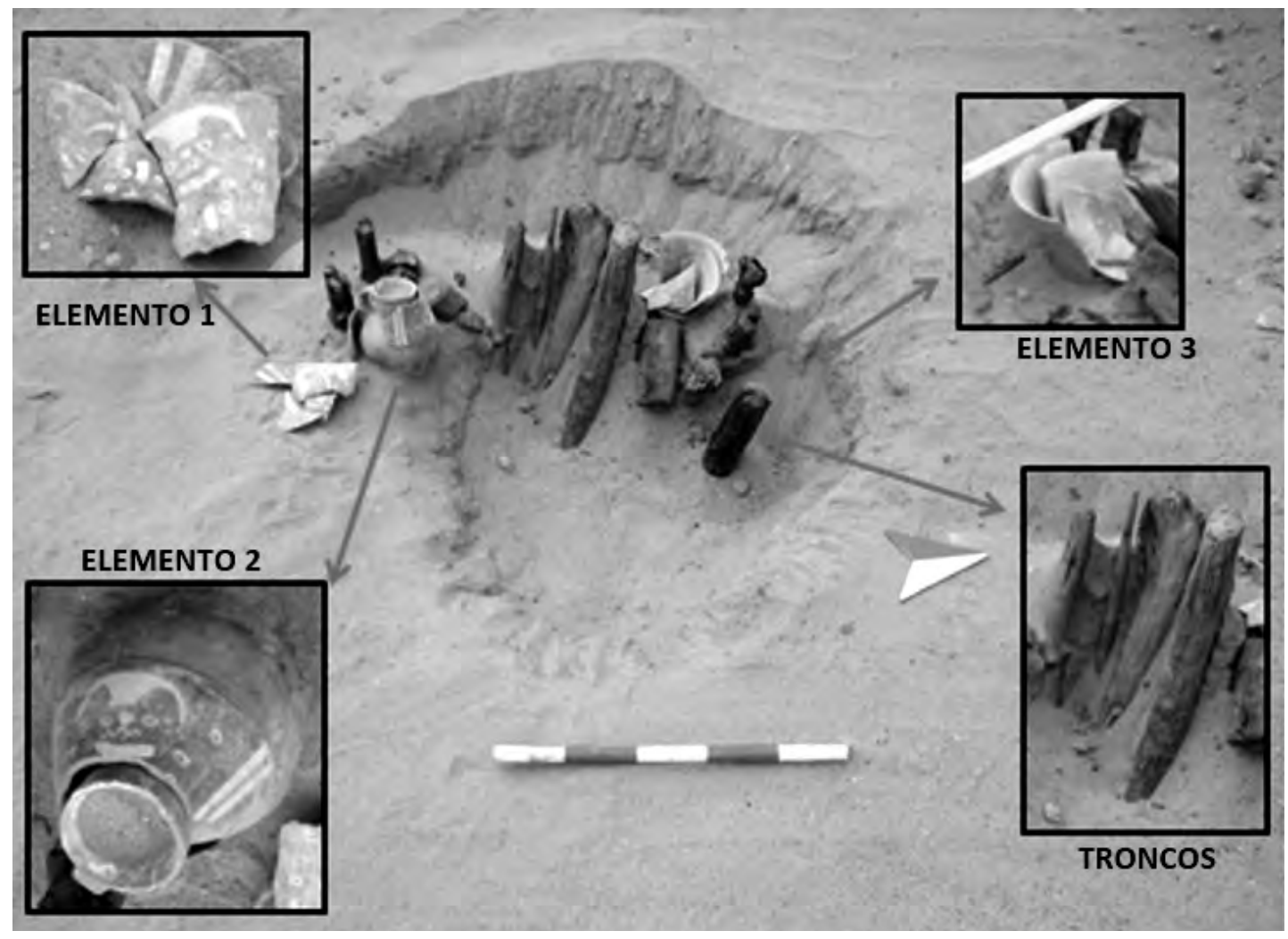

Figura 7: Vista en detalle de los elementos del nivel I, Contexto Funerario 12, Unidad 13, Cerro Colorado. 
Elemento 8: Olla de forma globular achatada, de cuello en forma acampanada corta, con dos asas cintadas laterales de forma vertical.

Elemento 9: Olla de forma globular, de cuello corto de forma globular con dos asas cintadas laterales de forma vertical, de la cuales una se encuentra mutilada.

Elemento 10: Vasija abierta en forma de plato de base cónica, se encuentra a manera de tapa del elemento 11.

Elemento 11: Cántaro pequeño de cuerpo globular, de cuello recto divergente. Presenta decoración variada en la parte exterior de su estructura.

Elemento 12: Figurina antropomorfa (cuchimilco), presenta decoración variada y se encuentra al oeste del individuo.

Elemento 13: Figurina antropomorfa (cuchimilco), presenta decoración variada y se encuentra al este del individuo. fardo.

Elemento 14: Restos de metal correspondiente a metal (cobre), la cual se encontraba encima del

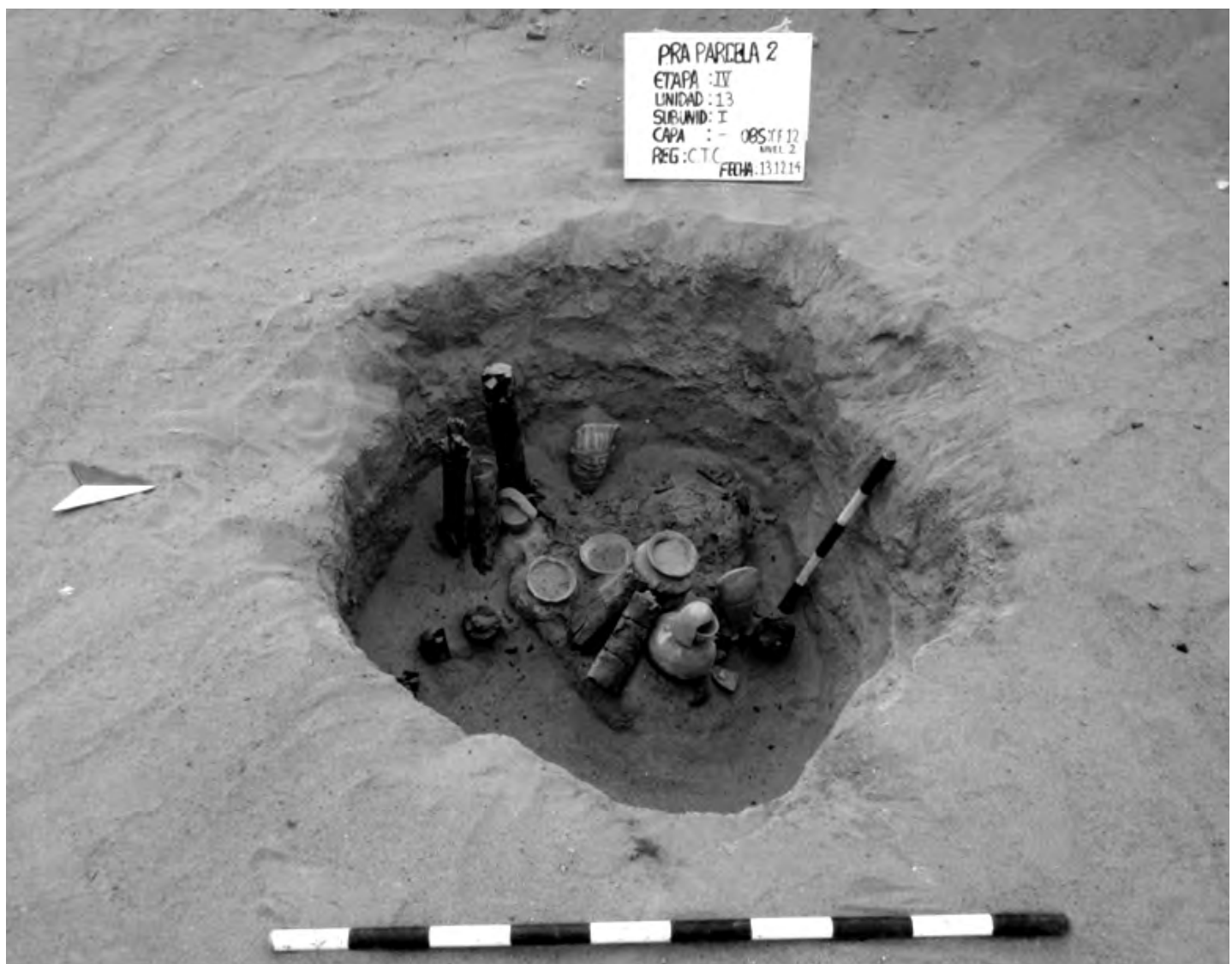

Figura 8: Vista en detalle del Nivel II, Contexto Funerario 12, Unidad 13, Cerro Colorado. Nótese la matriz funeraria $y$ los elementos conformantes. 


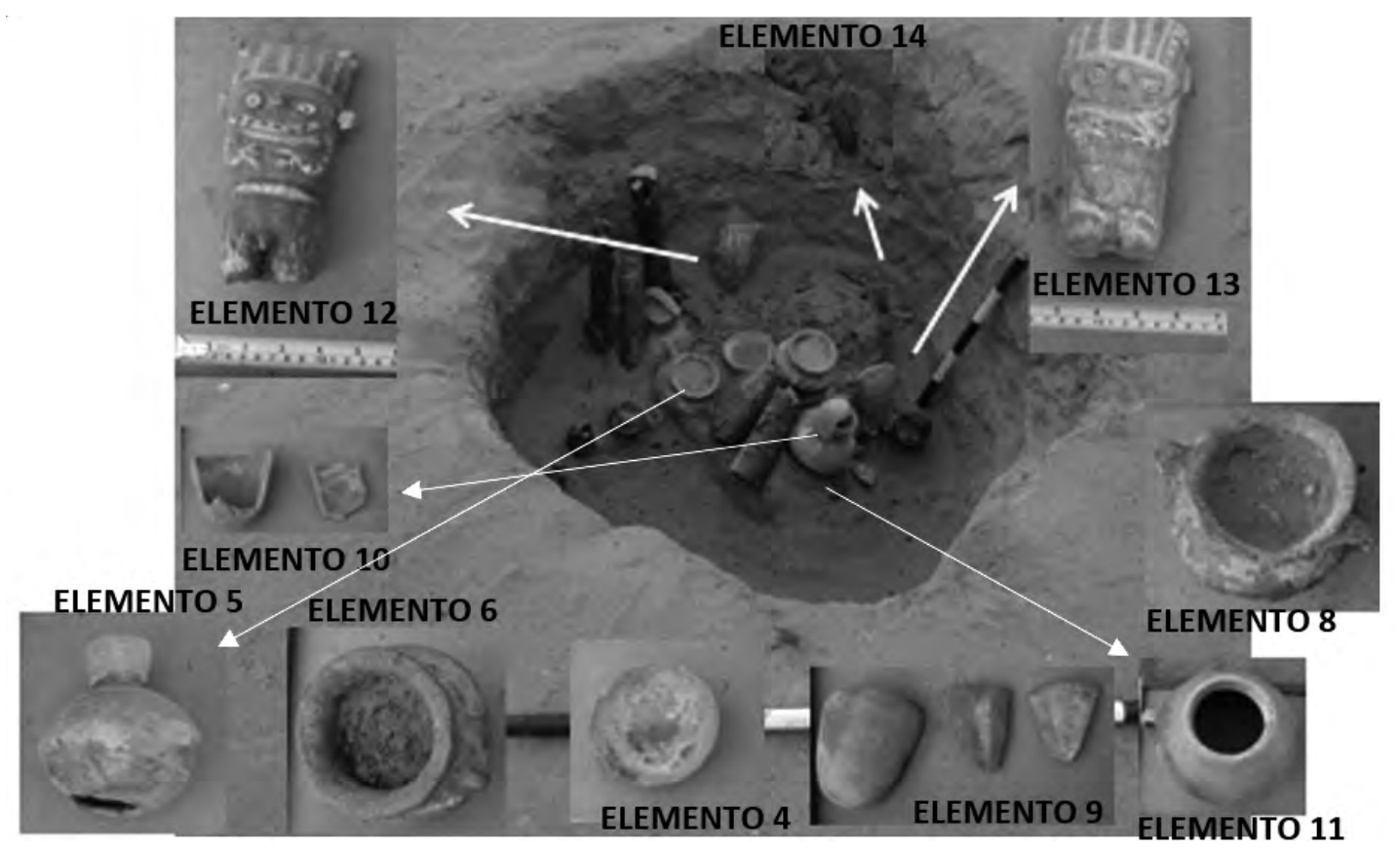

Figura 9: Vista en detalle de los elementos del nivel II, Contexto Funerario 12, Unidad 13, Cerro Colorado.

Las dos figurinas (cuchimilcos) son de estilo Chancay, dispuestas hacia ambos lados del individuo y mirándose entre sí.

Nivel III: Los componentes de este nivel son:

Individuo: En este nivel se identificó al individuo, el cual se presenta completamente enfardelado. Es un individuo adulto en posición decúbito dorsal y orientado hacia el este. Una particularidad del enfardelamiento es que está rellenado a base de hojas.

Asociaciones: En este nivel se identificó entre las asociaciones vasijas cerámicas (elementos), metales (cobre) y los troncos de madera (extensión de los niveles I y II) de diversos tamaños y formas. Se encuentra al ras y por debajo del nivel del individuo.

Elemento 15: Vasija pequeña abierta a manera de un tazón de base plana. Se encuentra encima del elemento 16.

Elemento 16: Cántaro pequeño de forma globular, de cuello acampanado, con dos asas cintadas laterales entre el cuello y la parte superior del cuerpo.

Elemento 17: Olla de forma ovoide, de cuello acampanado y divergente, con dos asas cintadas laterales de forma vertical. Asimismo, presenta quema en casi todo el cuerpo.

Elemento 18: Olla pequeña de forma globular de cuello acampanado, con dos asas cintadas laterales de forma horizontal, aunque una de ellas se encuentra mutilada. Asimismo, presenta quema en casi todo el cuerpo.

Elemento 19: Olla pequeña de forma globular achatada, de cuello corto, con dos asas cintadas laterales de forma vertical, presenta quema en todo el cuerpo. 


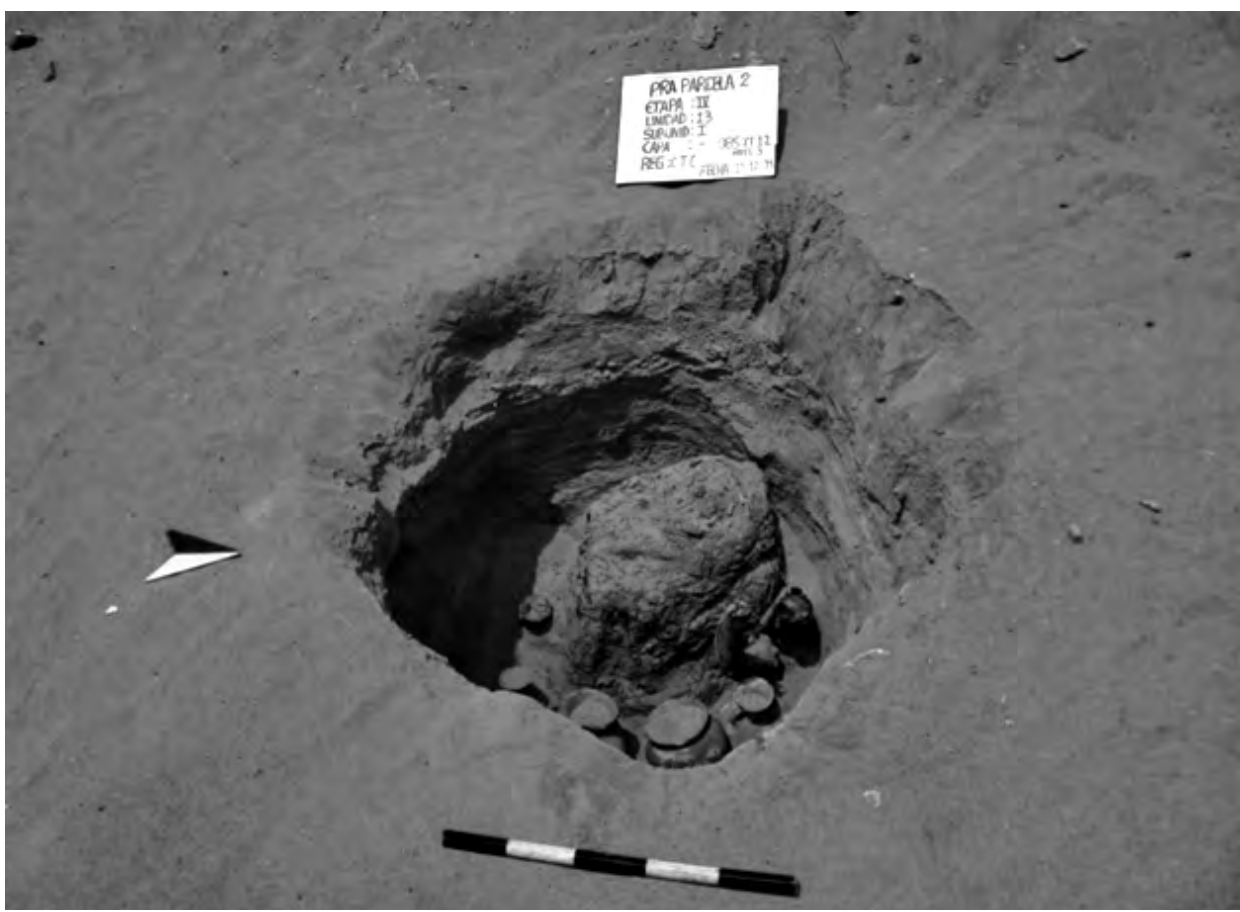

Figura 10: Vista en detalle del Nivel III, Contexto Funerario 12, Unidad 13, Cerro Colorado. Nótese la matriz funeraria $y$ los elementos conformantes.

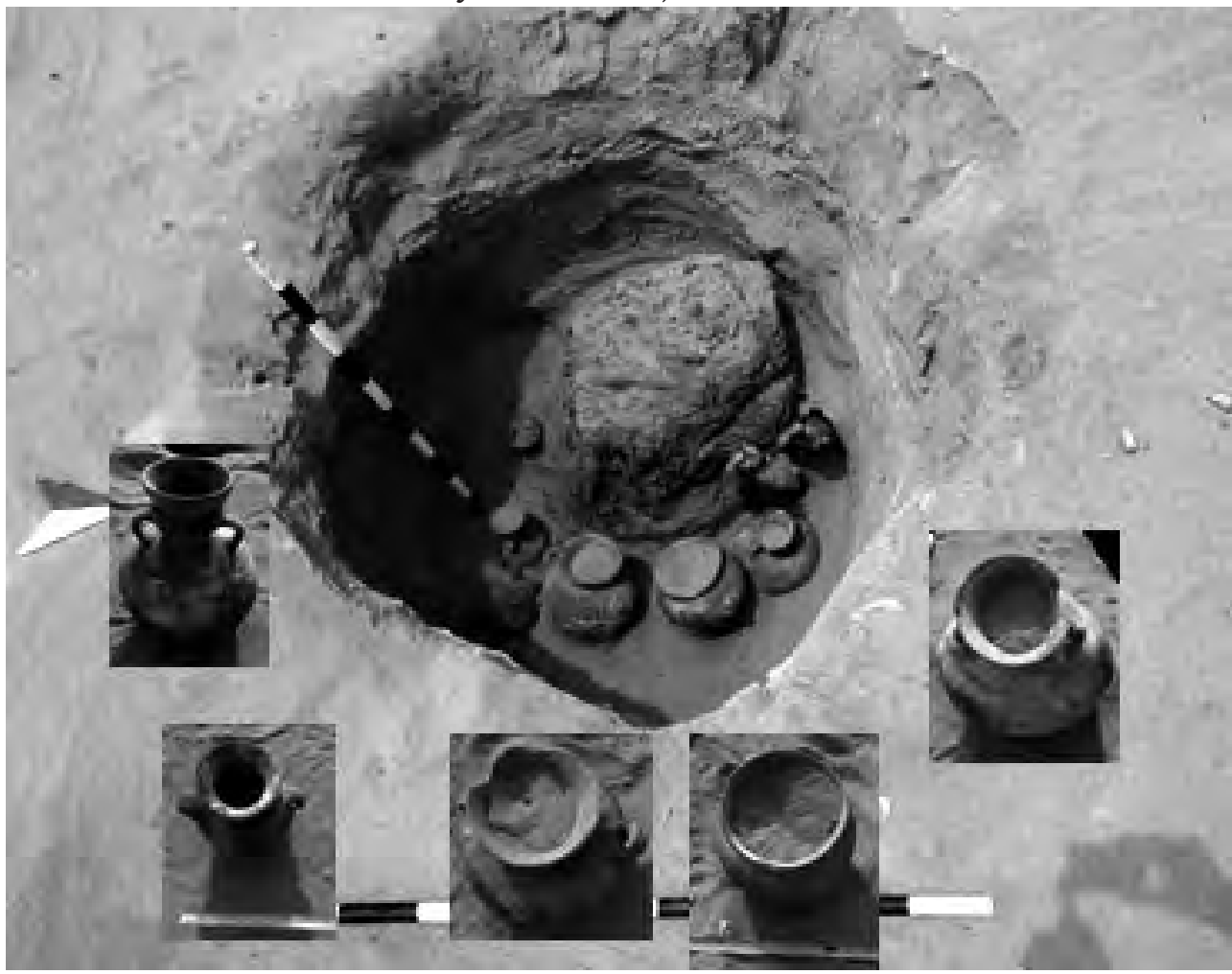

Figura 11: Vista en detalle de los elementos del nivel III, Contexto Funerario 12, Unidad 13, Cerro Colorado. 
Pieter van Dalen, Roberto Tello y Hans Grados / Un contexto funerario del horizonte medio...

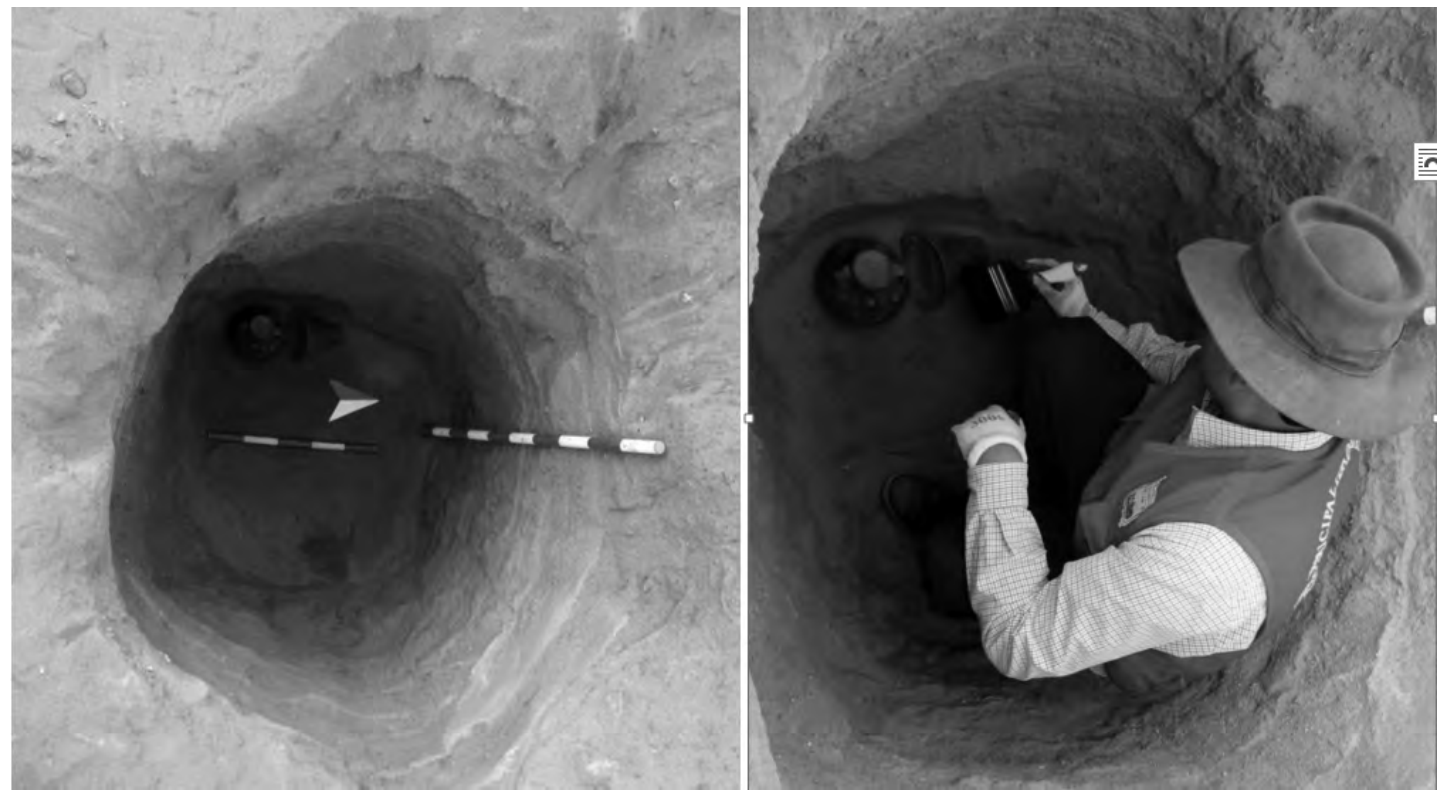

Figuras 12 y 13: Dos vistas de los elementos 21 y 22, ubicados debajo del fardo, nivel III, Contexto Funerario 12, Unidad 13, Cerro Colorado.

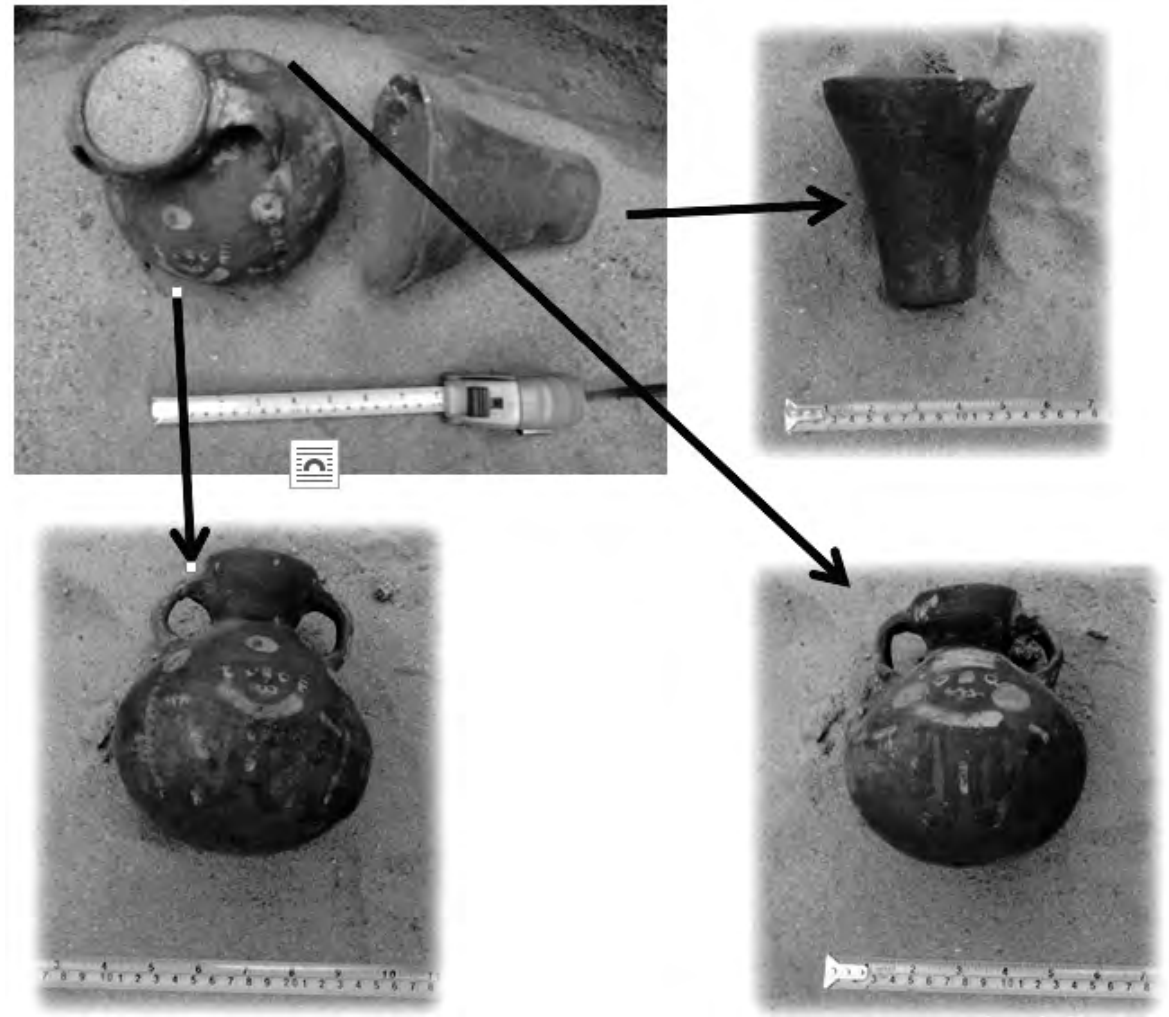

Figura 14: Vista de los elementos 21 y 22, ubicados debajo del fardo, conformados por vasijas de estilo Humaya. 


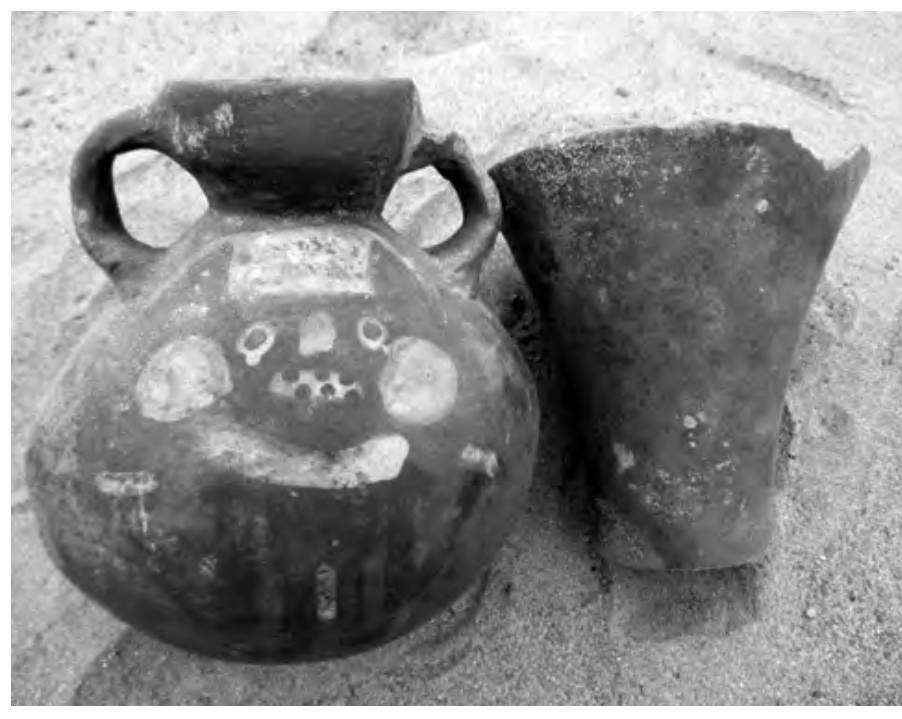

Figura 15: Vista en detalle de los elementos 21 y 22, ubicados debajo del fardo, conformados por vasijas de estilo Humaya.
Elemento 20: Cántaro de forma globular, de cuello acampanado con dos asas cintadas laterales de forma vertical. Asimismo, las asas están diseñadas como si fueran sogas.

Elemento 21: Vaso de forma acampanada. Presenta pulido y es de color rojizo. Se ubica debajo del fardo.

Elemento 22: Cántaro de forma globular achatada, de cuello acampanado. Posee dos asas cintadas laterales de forma vertical entre el cuello y la parte superior del cuerpo. Presenta pulido y es de color rojizo. Asimismo, se observa decoración variada hacia ambos lados externos de la vasija. Se trata de dos personajes antropomorfos. Se ubica debajo del fardo.

\section{ANÁLISIS Y DISCUSIÓN DE LOS RESULTADOS}

Son escasos los trabajos que reportan las características de las áreas funerarias y los contextos funerarios en la costa Norcentral durante los periodos Horizonte Medio e Intermedio Tardío (Cárdenas 1977, Córdova 2003, Cornejo 1991, 1992, Fung 1960, Kaulicke 1997, 2000, Krzanowski 1991a, Ruiz 1981, 1990, 1991, 1998a, 1998b, 1999, 2007, Stumer 1952, Vallejo 2010 y van Dalen 2007, 2008, 2013). El complejo arqueológico de Cerro Colorado en el valle de Huaura se constituye en el área funeraria más extensa de toda la costa central peruana, cuya importancia ha sido descrita por varios investigadores, así como el sector del tambo de datación durante el Tawantinsuyu (Cárdenas 1988, Horkheimer 1965, Krzanowski 1991b, Miasta y Merino 1986, Ruiz 1981, 1990, 1991, 1998a, 1998b, 1999, 2007, Tosso 2000, Vallejo 2010 y van Dalen 2004, 2011).

El contexto funerario 12 de la unidad 13, recuperado en el área de la IV Etapa de la Asociación Los Pinos en el valle de Huaura, constituye una evidencia de gran importancia para la mejor comprensión del Periodo Horizonte Medio en este valle. Pues, los materiales culturales que conforman las asociaciones del contexto, en especial la cerámica, son materiales pertenecientes a estilos del Periodo Horizonte Medio. Las dos vasijas más representativas que fueron halladas en el fondo de la estructura funeraria y debajo del fardo, corresponden al estilo Humaya, estilo cerámico correspondiente al Horizonte Medio 3 que está asociado con la cultura Huaura y el estilo del mismo nombre, entidad sociopolítica que se desarrolló en la segunda mitad de este periodo en el valle de Huaura (van Dalen 2007). El estilo Humaya fue definido por primera vez por Julio C. Tello durante sus exploraciones en el valle de Huaura, se caracteriza por presentar mayormente cántaros de cuerpo ovalado, con las caras anterior y posterior achatadas, con dos asas cintadas laterales y con engobe total en color rojo ladrillo (muy similar al engobe Teatino); presentando en las caras anterior y posterior un personaje antropomorfo, pintado en variados colores, con tocados sobre la cabeza o atavíos en la cara (orejeras), con las extremidades superiores extendidas o cogiendo báculos o varas, de clara influencia norteña. Por su parte, vasijas del estilo Huaura está también presente entre las asociaciones del contexto funerario 13, este 
Norcentral, desde Ancón hasta el valle de Huarmey y por lo general se le encuentra asociado con otros estilos locales del mismo periodo (Teatino, Humaya, Pativilca - Supe, Pampa de Animas, entre otros) al interior de estructuras funerarias (van Dalen 2007, 2012, 2013, Kaulicke 1997).

Un aspecto importante que llama la atención, es la presencia de tres niveles horizontales de materiales asociados, hecho que otros autores habían reportado para la cultura Chancay (Cornejo, 1991, 1992). Los materiales más recurrentes (casi en un $85 \%$ ) en las asociaciones son las vasijas, principalmente ollas, cántaros, cuencos y platos, estas dos últimas formas casi siempre colocadas en posición invertida a modo de tapas de los cántaros de mayor tamaño.

Es importante la presencia de figurinas antropomorfas tipo cuchimilco, las cuales se presentan en el segundo nivel (Nivel II), uno hacia cada lado del fardo y mirándose entre sí. En muchos otros contextos funerarios recuperados de Cerro Colorado (Parcela 2) hemos recuperado estas figurinas, siempre acompañando al individuo al interior de la estructura funeraria y en varios casos la presencia de varios de estos se da en asociación escénica, relacionado al parecer con pasajes de la vida del difunto o del ritual funerario desarrollado durante el entierro. Algunos autores han descrito la presencia de estas figurinas en contextos funerarios de la cultura Chancay (Horkheimer 1972, Morgan 1991, Silva 2009, van Dalen 2008, 2013).

Cabe notar además, que contra lo que se creía que el uso de fardo en el tratamiento de los individuos era una característica propia de la sociedad Chancay, el hallazgo del individuo al interior de un fardo rellenado con restos botánicos (hojas) hace ver que esta fue una práctica desarrollada desde el Periodo Horizonte Medio por la sociedad Huaura, antecesora de los Chancay en el valle de Huaura.

La presencia de troncos de madera (al igual que cañas gruesas), dispuestas en posición vertical hacia los costados del fardo, es una característica de los contextos funerarios Chancay reportado por algunos investigadores (Kaulicke 1997, van Dalen 2013), práctica mortuoria que se inicia desde el Periodo Horizonte Medio. Los troncos simbolizan cierto poder o status que presentaba el individuo en su sociedad.

El uso de cobre como parte de las asociaciones es también una constante en los contextos funerarios del Horizonte Medio para el valle de Huaura, siendo muy común su presencia en el interior de la boca de los individuos o colocado sobre la cara.

\section{BibliografÍA}

\section{CARDENAS MARTIN, Mercedes}

1977 Informe preliminar del trabajo de campo en el valle de Huaura, departamento de Lima, agosto de 1977. Pontificia universidad católica del Perú. PUCP, Seminario de arqueología. Lima, 74 pp.

1977-78 Obtención de una cronología del uso de los recursos marinos en el antiguo Perú. Boletín de Arqueología PUCP: Boletín del seminario de arqueología. No. 19-20. Lima, pg. 19-20.

1988 Arquitectura prehispánica del valle de Huaura. Simposio de Arquitectura y Arqueología. CONCYTEC. Victor Rangel Flores. Chiclayo, pp. 101-114.

\section{CORDOVA HERRERA, Martin}

2003 Rescate Arqueológico de San José de Manzanares. Boletín del patronato de defensa del patrimonio cultural de los valles de Huaura y Ambar № 11, año II, Junio. pp. 1 - 8 
CORNEJO GUERRERO, Miguel

1991 Patrones Funerarios y discusión cronológica en Lauri, valle de Chancay. Estudios sobre la cultura Chancay, Perú. Krakow., Polonia. pp 83 - 113.

1992 Cronología y costumbres sepulcrales en Lauri, valle de Chancay. Estudios de Arqueología Peruana. D. Bonavía ed., Fomciencias, Lima.

FUNG PINEDA, Rosa

1960 Huaral: Inventario de una tumba saqueada. Etnología y Arqueología, año 1, No 1. Lima. pp $74-129$.

HORKHEIMER, Hans

1965 Identificación y bibliografía de importantes sitios prehispánicos del Perú. Arqueológicas № 8 M.N.A.A.H.P. Lima

1972 Chancay prehispánico: Diversidad y belleza. 100 años de arqueología en el Perú, R. Ravines, comp. Petroperú

\section{KAULICKE, Peter}

1997 Patrones funerarios en Ancón. Fondo editorial Universidad Católica.

2000 Memoria y muerte en el antiguo Perú. Pontificie Universidad católica del Perú. Fondo Editorial. KRZANOWSKI, Andrzej

1991a Chancay: una cultura desconocida. Estudios sobre la cultura Chancay, Perú. Krakow, pp. 19-36

1991b Influencia inca en los valles de Huaura y Chancay. Estudios sobre la cultura Chancay, Perú. Krakow, pp. 189-214

MEDINA , Phelippe de

1986 (1650) Relación del Lixcenciado Phelippe de Medina visitador general de las idolatrías del Arcobispado de Lima, embiada al Ilustrisimo y Reverendisimo señor arzobispo della en que le da quenta de las que se han descubierto en el pueblo de Huacho donde a comencado a visitar desde 19 de febrero hasta 23 de marco de 1650. Antología general de la Prosa en el Perú: Los orígenes. De lo oral a lo escrito. Tomo I. Edubanco. Lima, pg. 229 - 240.

MIASTA GUTIERREZ, Jaime; MERINO JIMENEZ, Manuel

1986 Inventario y catastro de monumentos arqueológicos del valle de Huaura. Seminario de Historia Rural Andina. UNMSM. Lima, 151 pgs.

MORALES CAUTI, Héctor

2009 Informe final del Proyecto de rescate Arqueológico Complementario en la Parcela 3, sitio arqueológico de Cerro Colorado, Areas Ocupadas II, III, IV y V, Asociaciones de Vivienda Palmeras Unidas y Cerro Colorado, distrito de Santa María, Provincia de Huaura. Informe final presentado al INC.

MORGAN, Alexandra

1991 Las figurinas humanas de cerámica de la cultura Chancay. Estudios sobre la cultura Chancay, Perú. Krakow pg. 155-187. 


\section{RODRIGUEZ GUILLÉN, Luis}

2007 Informe final del Proyecto de Rescate Arqueológico en la Parcela 3 del sitio Cerro Colorado - Huacho. Informe final presentado al Instituto nacional de Cultura. 124 pp. mas planos.

\section{RUIZ ESTRADA, Arturo}

1981 Investigaciones arqueológicas en Cerro Colorado. Informe de avance, Universidad nacional José Faustino Sánchez Carrión. Huacho, 14 pgs.

1990 Notas sobre un quipu de la costa nor-central del Perú. Quipu y Yupana: colección de escritos. Consejo nacional de ciencia y tecnología. CONCYTEC. Lima, Pp. 191-194.

1991(a) El entierro de un músico Prehispánico en Huacho, valle de Huaura. Estudios sobre la cultura Chancay, Perú. Krakow., Polonia. Pg. 133 - 153

1998 (a) Sobre el hallazgo de momias tatuadas en Huacho. Revista INSULA № 4, Febrero Pg. 6-7.

1998 (b) "Sobre el hallazgo de momias tatuadas en Huacho". Boletín del Museo de Arqueología y Antropología, № 3, Universidad Nacional Mayor de San Marcos. Lima, Pp. 4.

1999 Textilería prehispánica Chancay = Pre-hispanic Chancay textiles. Tejidos milenarios del Perú = Ancient peruvian textiles (Colección Apu). AFP Integra - Wiese Aetna. Lima, Pp. 505-535.

2007 Notas sobre el entierro de un niño de la cultura Chancay de Huacho. Investigaciones Sociales. Revista del Instituto de Investigaciones Histórico Sociales. Facultad de Ciencias Sociales. Universidad nacional Mayor de San Marcos. № 18, Agosto. Lima, Pp. 151-177.

SILVA ESQUÉN, Miguel

2009 Análisis de figurinas del valle de Huaura. Revista Cultural Kullpi. Investigaciones culturales en la provincia de Huaral y el Norte Chico. Año 4, No 4, octubre del 2009. Lima, pp. $77-94$.

STUMER, Louis

1952 Investigaciones de superficie en Caldera, valle de Huaura. Revista del Museo Nacional, № 21, Lima, pp. 38-67.

TOSSO MORALES, Walter

2000 Informe final del Proyecto de Estudio de Evaluación Arqueológica en la modalidad de evaluación, Prospección y Reconocimiento sistemático con excavaciones en el Asentamiento Humano Alberto Fujimori entregado al INC. Informe final presentado al INC.

VALLEJO, Francisco

2010 Evidencias arqueológicas de un nuevo estilo cerámico en el valle de Huaura para el Periodo Intermedio tardío: El paso del Horizonte Medio al Intermedio tardío. Arqueología en el Perú. Nuevos aportes para el estudio de las sociedades andinas. Rubén Romero y Trine Pavel editores. Lima, pp. 229-248.

\section{VAN DALEN LUNA, Pieter}

2004 Los valles de Huaura y Chancay dentro del imperio del Tahuantinsuyo. Boletín del patronato de defensa de los valles de Huaura y Ambar. № 16, año III, junio. Pgs. 3 - 8 
2007 Resultados de las investigaciones arqueológicas en Pampa de Animas, valle de Huaura. Guara № 3. Museo Arqueológico de la UNJFSC. Huacho, noviembre del 2007, pg.16 - 24.

2008 Los ecosistemas arqueológicos en la cuenca baja del río Chancay-Huaral. Su importancia para el desarrollo de las formaciones sociales prehispánicas. Ed. Gutemberg. Lima, 185 pgs.

2011 El Tawantinsuyu en la costa Norcentral peruana: valles de Chancay y Huaura. Investigaciones Sociales, № 27. Revista del Instituto de Investigaciones Histórico Sociales. Facultad de Ciencias Sociales, Universidad Nacional Mayor de San Marcos. Lima, pp. 77-104.

2012 Análisis arquitectónico y secuencias de ocupación en el sitio de pampa de Animas - La Wasa, Luriama, Campiña de Santa María, valle de Huaura. Kullpi. Investigaciones culturales en la provincia de Huaral y el norte chico. № 6. Lima, pp. 67-118.

2013 Contextos funerarios Chancay en Macatón, valle de Chancay-Huaral. Arqueología y Sociedad. № 25. Museo de Arqueología y Antropología de San Marcos. Universidad Nacional Mayor de San Marcos. Lima, pp. 259-302.

VAN DALEN LUNA, Pieter; GRADOS RODRIGUEZ, Hans; TELLO CUADROS, Roberto; VIVANCO, Iván; FLORES LIVIA, Wendy; y MARCELO GONZÁLES, Yerovi

2014 Resultados del proyecto de rescate arqueológico en el área de la parcela 4 y 5 del sitio arqueológico Cerro Colorado, Santa María, provincia de Huaura. Kullpi. Investigaciones culturales en la provincia de Huaral y el Norte Chico. Año 7, No 7, Lima, pp. 189-216.

VAN DALEN LUNA, Pieter; CARBONEL ARANA, Dayanna

2015 Contextos funerarios Chancay en macatón, valle de Chancay-Huaral. Arqueología y Sociedad. № 29. Museo de Arqueología y Antropología de San Marcos. Universidad Nacional Mayor de San Marcos. Lima, En prensa. 